\title{
Pituitary tumor transforming gene-1 haplotypes and risk of pituitary adenoma: a case-control study
}

\author{
Shuai Chen ${ }^{1}$, Lan Xiao², Zhixiong Liư', Jinfang Liu and Yunsheng Liu*
}

\begin{abstract}
Background: It has been suggested that pituitary adenoma results from accumulation of multiple genetic and/or epigenetic aberrations, which may be identified through association studies. As pituitary tumor transforming gene1 (PTTG1)/securin plays a critical role in promoting genomic instability in pituitary neoplasia, the present study explored the association of PTTG1 haplotypes with the risk of pituitary adenoma.

Methods: We genotyped five PTTG1 haplotype-tagging SNPS (htSNP) by PCR-RFLP assays in a case-control study, which included 280 Han Chinese patients diagnosed with pituitary adenoma and 280 age-, gender- and geographically matched Han Chinese controls. Haplotypes were reconstructed according to the genotyping data and linkage disequilibrium status of the htSNPs.

Results: No significant differences in allele and genotype frequencies of the htSNPs were observed between pituitary adenoma patients and controls, indicating that none of the individual PTTG1 SNPs examined in this study is associated with the risk of pituitary adenoma. In addition, no significant association was detected between the reconstructed PTTG1 haplotypes and pituitary adenoma cases or the controls.

Conclusions: Though no significant association was found between PTTG1 haplotypes and the risk of pituitary adenoma, this is the first report on the association of individual PTTG1 SNPS or PTTG1 haplotypes with the risk of pituitary adenoma based on a solid study; it will provide an important reference for future studies on the association between genetic alterations in PTTG1 and the risk of pituitary adenoma or other tumors.
\end{abstract}

\section{Background}

Pituitary tumors are commonly encountered benign monoclonal adenomas that arise from cells of the anterior pituitary gland, accounting for approximately $15 \%$ of all diagnosed intracranial tumors [1]. These monoclonal tumors arise from highly differentiated cells expressing hormone gene products, including growth hormone, prolactin, adrenocorticotrophic hormone, thyroid-stimulating hormone, follicle-stimulating hormone and luteinizing hormone. Pituitary adenomas may be functional and actively secrete hormones, leading to characteristic clinical features such as acromegaly, Cushing's disease and hyperprolactinaemia. Commonly, they are non-functional, leading primarily to hypogonadism and compressive pituitary

\footnotetext{
* Correspondence: xyliuys@163.com

'Gamma Knife Treatment and Research Center, Xiangya Hospital, Central

South University, Changsha, 410008 PR China

Full list of author information is available at the end of the article
}

failure [1]. Previous longitudinal incidence surveys reported that the prevalence of pituitary adenoma had been steadily rising over the last decades [2,3]. A latest epidemiological study based on a well-defined population in the UK reveals that the prevalence of pituitary adenoma is $77.6 / 100,000$, about four-fold higher than previously thought [4].

Several genetic and epigenetic alterations have been observed in pituitary tumorigenesis. In addition to classic cancer genes $[5,6]$, there are a significant number of genetic or epigenetic alterations in pituitary tumors that target cell cycle regulators [7]. A completely new cell cycle pathway involved in pituitary oncogenesis is represented by pituitary tumor transforming gene-1 (PTTG1)/securin, an oncogenic molecule first identified in GH4 rat pituitary tumor cells [8]. Playing multiple roles in cell cycle regulation at different stages, PTTG1 is involved in the mitotic checkpoint that prevents

C Biomed Central

(c) 2011 Chen et al; licensee BioMed Central Ltd. This is an Open Access article distributed under the terms of the Creative Commons Attribution License (http://creativecommons.org/licenses/by/2.0), which permits unrestricted use, distribution, and reproduction in any medium, provided the original work is properly cited. 
abnormal chromosome segregation [7]. It is overexpressed in a variety of endocrine-related tumors, especially pituitary, thyroid, breast, ovarian, and uterine tumors, as well as nonendocrine-related cancers in the central nervous, pulmonary, and gastrointestinal systems [9]. Increased PTTG1 mRNA expression in pituitary tumor tissue has been confirmed in several studies $[10,11]$.

While many studies are focused on exploring the PTTG1-mediated tumorigenic mechanisms, none was conducted to study the association of genetic alterations in PTTG1 with the risk of pituitary adenoma. In the present study, we are the first to have investigated the association of individual PTTG1 SNPs or PTTG1 haplotypes with the risk of pituitary adenoma. To comprehensively study the genetic variants of PTTG1 associated with susceptibility to pituitary adenomas, we genotyped five PTTG1 haplotypetagging SNPs (htSNP) using PCR-RFLP in a case-control study, which included 280 pairs of age-, gender- and geographically matched Han Chinese people. The five htSNPs, including one in the 5'-flanking region, three in the intronic regions, and one in the 3'-flanking region of the PTTG1 gene, appropriately capture all the common haplotype blocks reconstructed in HapMap Phase III data [12].

\section{Methods}

\section{Specimens}

Blood specimens were collected from 280 Han Chinese patients diagnosed with pituitary adenoma at Xiangya Hospital of Central South University between October 2008 and August 2010. None of the patients had received any treatment before blood sampling. As controls, blood samples were collected from 280 age-, gender- and geographically matched Han Chinese individuals without a history of tumor at Xiangya Hospital of Central South University between May and December, 2007. None of the subjects had a family history of pituitary adenoma. None of the pituitary adenoma patients had a history of familial Cushing's syndrome, multiple endocrine neoplasia type 1 (MEN1) or carney complex. Blood specimens were obtained after informed consent from all subjects. This study was approved by the Ethic Committee of Xiangya Hospital.

\section{Tagging SNP Selection}

HapMap SNP Phase III data [12] were used to determine the frequency of SNPs among Han Chinese. Eighty-four SNPs were obtained from a 17.52-kb region of PTTG1 from $2 \mathrm{~kb}$ upstream of the transcriptional start site to $4 \mathrm{~kb}$ downstream of the 3' untranslated region. Tagging SNP selection was done using the Haploview program. The Haploview program implemented a htSNP selection method proposed by Carlson and colleagues, which selects a set of htSNPs such that each SNP considered has $r^{2}$ greater than a prespecified threshold with at least one of the htSNPs [13]. In our selection, only SNPs with minor allele frequency greater than $10 \%$ were considered, and the threshold of pairwise linkage disequilibrium (LD) was set as $r^{2}=0.8$. A total of five htSNPs were selected among 84 SNPs considered across PTTG1, including one in the 5'-flanking region, three in the intronic regions, and one in the 3'-flanking region (Additional file 1).

\section{Genotyping}

Genomic DNA from blood specimens was isolated using standard proteinase $\mathrm{K}$ digestion and phenol-chloroform extraction. The five PTTG1 htSNPs were amplified by PCR. The sequences of PCR primers are reported in Additional file 2. The PCR reaction was carried out in a total volume of $25 \mu \mathrm{L}$, containing 50 to $100 \mathrm{ng}$ of genomic DNA, 1 unit of Premix Taq ${ }^{\mathrm{TM}}$ DNA polymerase (Takara, Japan), $0.2 \mu \mathrm{mol} / \mathrm{L}$ of each primer, $1 \times$ Ex Taq Buffer (Mg2+ Plus), $0.25 \mathrm{mmol} / \mathrm{L}$ of each deoxynucleotide triphosphate. Genotyping for the htSNPs was done by RFLP with restriction endonucleases (Additional file 2). The different alleles were identified on a $4 \%$ agarose gel and visualized with ethidium bromide.

\section{Linkage Disequilibrium (LD) and haplotype Analysis}

Pairwise measures of LD measured by Lewontin coefficient $\left(D^{\prime}\right)$ and squared correlation coefficient $\left(r^{2}\right)$ between the genotyped SNPs were calculated with the Haploview program [14]. The frequencies of individual haplotypes were estimated from the genotype data using the SHEsis program [15], which implement a FullPrecise-Iteration algorithm for reconstructing haplotypes. Haplotypes with a frequency less than 0.05 were not considered in the analysis. Logistic regression analysis was done using SAS PROC LOGISTIC to estimate the odds ratios (OR) and 95\% confidence intervals (95\% CI) of individual SNPs or haplotypes.

\section{Statistical Analysis}

Hardy-Weinberg equilibrium analysis for genotype distribution in controls was carried out by a Chi-square goodness-of-fit test. Differences in genotype and allele frequencies between cases and controls were determined using Chi-square test. Logistic regression was performed to assess OR and 95\% CI. All the statistical analyses were implemented with SAS 9.1.3. The statistical significance level of this study was set at two-sided $\alpha=0.05$.

\section{Results}

As this was an age- and gender-matched cases-control study, there was no significant difference in sex and age between pituitary adenomas patients and controls (Table 1), and therefore adjustment for age and sex was not needed in data analysis. 
Table 1 Characteristics of Study Samples

\begin{tabular}{lccc}
\hline & $\begin{array}{c}\text { Cases }(\mathbf{n}=\mathbf{2 8 0}), \\
\mathbf{n}(\%)\end{array}$ & $\begin{array}{c}\text { Controls }(\mathbf{n}=\mathbf{2 8 0}), \\
\mathbf{n}(\%)\end{array}$ & $\mathbf{P}^{*}$ \\
\hline $\begin{array}{l}\text { Age (mean } \pm \text { SD) } \\
\text { Gender }\end{array}$ & $42.7 \pm 13.5$ & $42.3 \pm 12.4$ & 0.745 \\
$\quad$ Male & $142(50.7)$ & $142(50.7)$ & 1.0 \\
$\quad$ Female & $138(49.3)$ & $138(49.3)$ & \\
Histology & & & \\
$\quad$ CA & $34(12.2)$ & & \\
SA & $32(11.4)$ & & \\
TA & $42(15)$ & & \\
LA & $84(30)$ & & \\
NCA & $88(31.4)$ & & \\
\hline
\end{tabular}

Note: $C A$, corticotrophic adenoma; SA, somatotrophic adenoma; TA, thyrotrophic adenoma; LA, lactotrophic adenoma (i.e. prolactinoma); NCA, null cell adenoma. *Two-sided Chi-square test was applied to Gender and independent $t$ test was applied to age.

As shown in Table 2, among the five htSNPs, rs2910201 and rs3811999 were found to depart significantly from Hardy-Weinberg equilibrium in controls and therefore excluded from later analyses. No significant difference in allele and genotype frequencies at any of the remaining three polymorphic sites (rs1895320, rs2910200, and rs68827420) was observed between pituitary adenoma patients and controls (Table 3).

$D^{\prime}$ value and $r^{2}$ for rs1895320, rs2910200, and rs6882742 were calculated according to the genotyping data reported in Table 3 . The different degrees of LD between cases and controls are summarized in Table 4 . LD maps measured by $D^{\prime}$ in cases and controls shows rs2910200 and rs6882742 were in LD with each other in both cases and controls $\left(D^{\prime}>0.8\right)$ (Figure 1). Moreover, rs1895320 and rs2910200 had weaker LD in cases $\left(D^{\prime}=0.012, r^{2}=0.0\right)$ than in controls $\left(D^{\prime}=1.0\right.$, $\left.r^{2}=0.026\right)$ (Table 4; Figure 1). According to the genotyping data in pituitary adenoma patients and controls, 2-SNP haplotypes (rs1895320 and rs2910200; rs2910200 and rs68827420) were reconstructed (Table 5). Haplotypes with frequencies greater than 0.05 were subject to further analysis. As shown in Table 5, three 2-SNP haplotypes for rs1895320 and rs2910200 or for

Table 2 Hardy-Weinberg Equilibrium (HWE) Test on Controls in the Study

\begin{tabular}{ccccc}
\hline $\begin{array}{c}\text { Restriction } \\
\text { Enzyme }\end{array}$ & $\begin{array}{c}\text { Reference } \\
\text { SNP ID (rs) }\end{array}$ & $\begin{array}{c}\text { HWE Test P } \\
\text { Value }\end{array}$ & $\begin{array}{c}\text { Chromosome } \\
\text { Position }\end{array}$ & $\begin{array}{c}\text { Minor } \\
\text { Allele }\end{array}$ \\
\hline Tsp45 I & rs1895320 & $>0.05$ & 159782164 & $\mathrm{C}$ \\
Bsl I & rs2910200 & $>0.05$ & 159782569 & $\mathrm{~T}$ \\
Mbo II & rs2910201 & $<0.001$ & 159782950 & $\mathrm{~T}$ \\
Mnl I & rs3811999 & $<0.001$ & 159779450 & $\mathrm{~T}$ \\
Bsl I & rs6882742 & $>0.05$ & 159790342 & $\mathrm{C}$ \\
\hline
\end{tabular}

Table 3 Genotype and Allelic Frequencies of PTTG1 htSNPs among Pituitary Adenoma Cases and Controls and Associations with Risk of Pituitary Adenoma

\begin{tabular}{|c|c|c|c|}
\hline & Cases/Controls & OR $(95 \% \mathrm{Cl})$ & $P$ \\
\hline \multicolumn{4}{|c|}{ rs1895320 } \\
\hline \multicolumn{4}{|c|}{ Genotype } \\
\hline CC & $2 / 4$ & $0.46(0.08-2.57)$ & $0.68^{\mathrm{a}}$ \\
\hline CT & $84 / 88$ & $0.91(0.64-1.31)$ & $0.67^{b}$ \\
\hline$\pi$ & 194/188 & 1.00 & $0.45^{c}$ \\
\hline \multicolumn{4}{|c|}{ Allele } \\
\hline$C$ & $88 / 96$ & $0.90(0.66-1.24)$ & \\
\hline $\mathrm{T}$ & $472 / 464$ & 1.00 & $0.52^{*}$ \\
\hline \multicolumn{4}{|c|}{ rs2910200 } \\
\hline \multicolumn{4}{|c|}{ Genotype } \\
\hline$\pi$ & $4 / 4$ & $1.12(0.27-4.58)$ & $0.73^{d}$ \\
\hline $\mathrm{TC}$ & $72 / 54$ & $1.48(0.99-2.22)$ & $0.06^{\mathrm{e}}$ \\
\hline CC & $202 / 222$ & 1.00 & $1.00^{f}$ \\
\hline \multicolumn{4}{|c|}{ Allele } \\
\hline $\mathrm{T}$ & $80 / 62$ & $1.35(0.95-1.93)$ & \\
\hline C & $476 / 498$ & 1 & $0.10^{*}$ \\
\hline \multicolumn{4}{|c|}{ rs6882742 } \\
\hline \multicolumn{4}{|c|}{ Genotype } \\
\hline CC & $4 / 10$ & $0.36(0.11-1.16)$ & $0.27^{9}$ \\
\hline CT & $90 / 104$ & $0.80(0.56-1.14)$ & $0.26^{h}$ \\
\hline$\pi$ & $176 / 166$ & 1.00 & $0.11^{\mathrm{i}}$ \\
\hline \multicolumn{4}{|c|}{ Allele } \\
\hline C & $98 / 124$ & $0.78(0.58-1.05)$ & \\
\hline $\mathrm{T}$ & $442 / 436$ & 1.00 & $0.10^{*}$ \\
\hline
\end{tabular}

Note: As certain genotypes have expected count less than 5 in cases or controls, separate Fisher's exact tests and Chi-square tests are performed where appropriate. a, Fisher's exact $P$ value for rs 1895320 CC vs. CT; b, Chisquare $P$ value for rs 1895320 CT vs. T; $c$, Fisher's exact $P$ value for rs 1895320 $C C$ vs. $T$; d, Fisher's exact $P$ value for rs 2910200 TT vs. TC; e, Chi-square $P$ value for rs2910200 TC vs. CC; f, Fisher's exact P value for rs2910200 TT vs. CC; $g$, Fisher's exact $P$ value for rs6882742 CC vs. CT; $h$, Chi-square $P$ value for rs6882742 CT vs. T; i, Fisher's exact P value for rs6882742 CC vs. T; *Chisquare $P$ value.

rs2910200 and rs6882742 accounted for $100 \%$ of the haplotypes in controls, respectively; the frequencies of all the 2-SNP haplotypes were not significantly different between pituitary adenoma patients and controls. In addition, no significant association was found between the 2-SNP haplotypes and histological classification of pituitary adenoma (data not shown).

Table $4 D^{\prime}$ and $r^{2}$ between Pairs of Three PTTG1 htSNPs in Pituitary Adenoma Cases and Controls

\begin{tabular}{ccc}
\hline htSNP Pairs & D' Cases/Controls $^{\prime}$ & r $^{2}$ Cases/Controls \\
\hline rs1895320 rs2910200 & $0.012 / 1.000$ & $0.000 / 0.026$ \\
rs1895320 rs6882742 & $0.595 / 0.764$ & $0.303 / 0.425$ \\
rs2910200 rs6882742 & $0.999 / 1.000$ & $0.038 / 0.035$ \\
\hline
\end{tabular}

Note: Values of $D^{\prime}$ and $r^{2}$ were calculated with the Haploview program. 


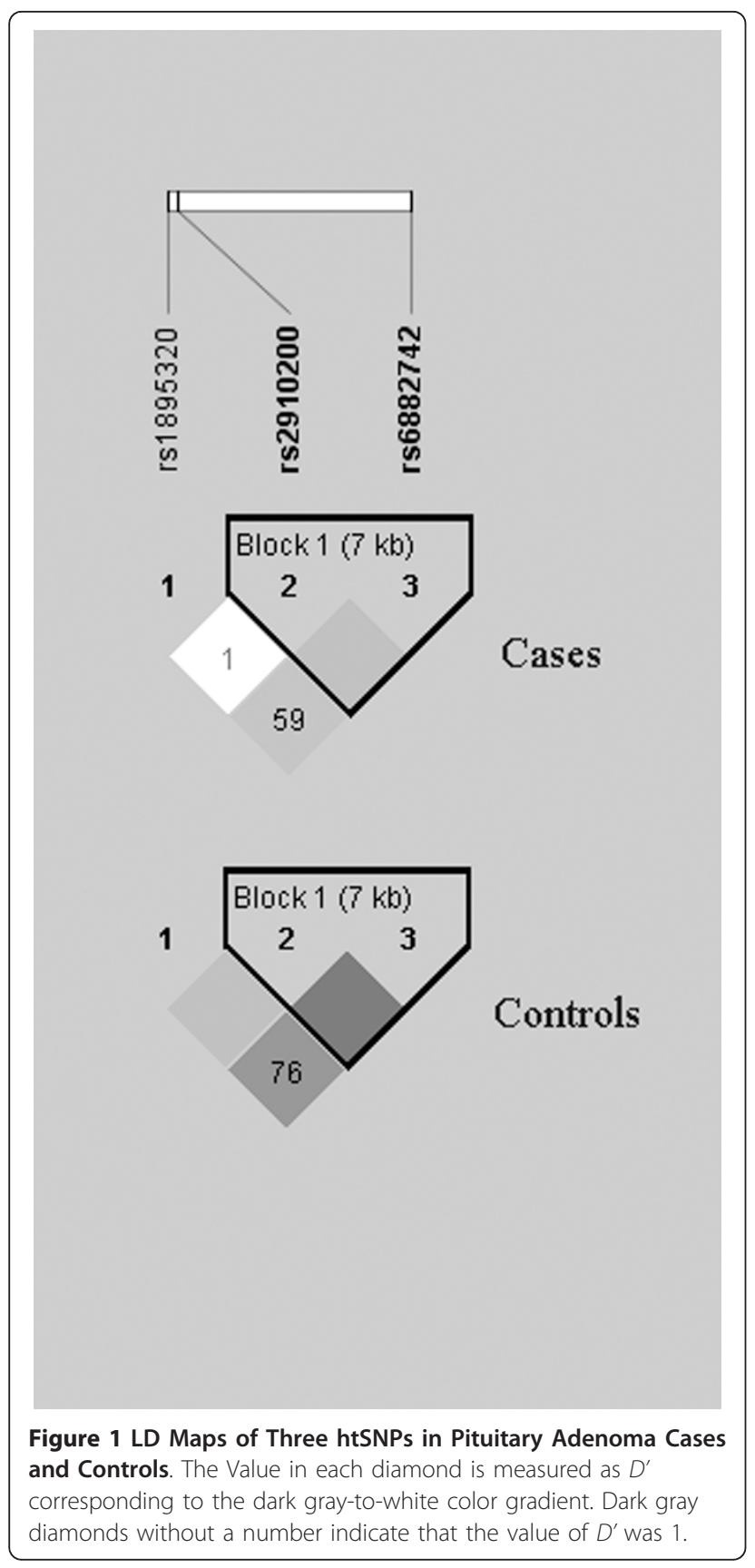

\section{Discussion}

Pituitary tumors are common intracranial neoplasms that cause significant morbidity through mass effects and/or inappropriate secretion of pituitary hormones [16]. The prevalence of pituitary adenoma has dramatically increased in the past decade [4].

PTTG1/securin is a vital component of the spindle checkpoint controlling faithful chromatid separation. It inhibits separase, the major effector for chromosome segregation during mitosis [17]. Overexpression of PTTG1 causes cell transformation and induces aneuploidy $[18,19]$, whereas either abundance or loss of it can lead to dysregulated G2/M checkpoint surveillance, resulting in abnormal mitosis and chromosomal instability. Absence of this gene results in a decrease in the incidence of pituitary tumors in pRB heterozygous mice, probably by triggering ARF/p53/p21-dependent senescence $[20,21]$. In contrast, overexpression PTTG1 in the pituitary in transgenic mice leads to pituitary hyperplasia and focal microadenomas [22]. All the previous findings indicate that PTTG1 is required for pituitary tumorigenesis, which warrant our study to explore possible association of genetic alterations in PTTG1 with the risk of pituitary adenoma, using htSNP and haplotype analyses to comprehensively capture various genetic variants of PTTG1 in a Han Chinese population. However, our results revealed no significant association between individual PTTG1 htSNPs or reconstructed PTTG1 haplotypes and the risk of pituitary adenoma, suggesting that genetic variation in PTTG1 is not an imporant contributing factor to pituitary tumorigenesis. PTTG1 seems to promote pituitary tumor formation through a variety of other ways.

Zhang et al. reported that PTTG1 mRNA was overexpressed in more than $90 \%$ of all types of pituitary tumors [10]. Based on our results, it seems that the PTTG1 mRNA overexpression in pituitary adenoma is more likely through epigenetic mechanisms rather than variation in the DNA sequence of PTTG1. Holt et al. reported that PTTG1 was regulated by cyclin-dependent kinase (CDK)-mediated phosphorylation [23], suggesting a link between the control of the cell cycle by CDKs

Table 5 Frequencies of Estimated 2-SNP Haplotypes of PTTG1 in Pituitary Adenoma Cases and Controls

\begin{tabular}{|c|c|c|c|c|c|c|}
\hline & \multicolumn{3}{|c|}{ rs1895320 - rs2910200 2-SNP Haplotype } & \multicolumn{3}{|c|}{ rs2910200 - rs6882742 2-SNP Haplotype } \\
\hline & CC & $\pi$ & $\mathrm{TC}$ & CC & $\pi$ & CT \\
\hline Cases (\%)/Controls (\%) & $13.4 / 17.1$ & 12.0/11.1 & $72.2 / 71.8$ & 18.2/22.1 & 14.5/11.1 & $67.2 / 66.8$ \\
\hline $\begin{array}{c}\text { OR } \\
(95 \% \mathrm{Cl})^{*}\end{array}$ & $\begin{array}{c}0.77 \\
(0.56-1.07)\end{array}$ & $\begin{array}{c}1.13 \\
(0.78-1.63)\end{array}$ & $\begin{array}{c}1.12 \\
(0.86-1.46)\end{array}$ & $\begin{array}{c}0.78 \\
(0.58-1.06)\end{array}$ & $\begin{array}{c}1.36 \\
(0.95-1.95)\end{array}$ & $\begin{array}{c}1.02 \\
(0.79-1.32)\end{array}$ \\
\hline$P$ & 0.120 & 0.532 & 0.416 & 0.107 & 0.089 & 0.865 \\
\hline
\end{tabular}

Note: Haplotypes with frequencies $>5 \%$ were included. ${ }^{*}$ Calculated with the SHEsis program. 
and PTTG1. Moreover, PTTG1 activates $\beta$-fibroblast growth factor, c-myc and cyclin D3 to enhance cell proliferation [24-26], and interacts with $\mathrm{Ku}$ and p53 to participate in DNA damage/repair and apoptosis [27]. Interplay between PTTG1 and the cell signaling molecules, rather than DNA sequence variation in the PTTG1 gene, may actually play an important role in pituitary tumorigenesis. Nevertheless, individual SNP analysis and/or haplotype analysis on genes of the interaction partners of PTTG1, or on newly identified candidate genes involved in pathogenesis of pituitary adenoma, such as the bone morphogenetic protein-4 (BMP-4) gene and the RWD-containing sumoylation enhancer (RSUME) gene [28], may yield interesting results.

\section{Conclusions}

Though no significant association was found between PTTG1 haplotypes and the risk of pituitary adenoma, this is the first report on the association of individual PTTG1 SNPs or PTTG1 haplotypes with the risk of pituitary adenoma based on a solid study; it will provide an important reference for future studies on the association between genetic alterations in PTTG1 and the risk of pituitary adenoma or other tumors.

\section{Additional material}

\section{Additional file 1: Haplotype Tagging SNPs of the PTTG1 Gene in the} Chinese Han Population. SNP position and minor allele frequency are based on HapMap SNP Phase III data http://hapmap.ncbi.nlm.nih.gov/cgiperl/gbrowse/hapmap28_B36. *Genotyped in reverse direction as opposed to $A / G$ in forward direction.

Additonal file 2: Primers and Restriction Endonucleases Used for PTTG1 Genotyping. *FP, Forward primer; RP, Reverse primer; $\neq$ The polymorphic alleles are identified following cleavage by restriction endonucleases, which yield fragments of different sizes for different alleles.

\section{Author details}

'Gamma Knife Treatment and Research Center, Xiangya Hospital, Central South University, Changsha, 410008 PR China. ${ }^{2}$ Cancer Research Institute, Central South University, Changsha, 410078 PR China.

\section{Authors' Contributions}

SC participated in study design, collected data, carried out data analysis, and drafted the manuscript. LX participated in study design, carried out data analysis, and performed data check and proofreading. ZL participated in data collection, carried out data analysis, and performed data check and proofreading. JL participated in study design, data collection and data analysis. YL participated in study design and data analysis, drafted the manuscript, and performed data check and proofreading. All authors have read and approved the final manuscript.

\section{Competing interests}

The authors declare that they have no competing interests.

Received: 6 December 2010 Accepted: 25 March 2011

Published: 25 March 2011
References

1. Chesnokova V, Melmed S: Pituitary Tumour-Transforming Gene (PTTG) and Pituitary Senescence. Horm Res 2009, 71:82-87.

2. Etxabe J, Gaztambide S, Latorre P: Acromegaly: an epidemiological study. J Endocrinol Invest 1994, 16:181-187.

3. Nilsson B, Gustavasson-Kadaka E, Bengtsson BA: Pituitary adenomas in Sweden between 1958 and 1991: incidence, survival and mortality. J Clin Endocrinol Metab 2000, 85:1420-1425.

4. Fernandez A, Karavitaki N, Wass JA: Prevalence of pituitary adenomas: a community-based, cross-sectional study in Banbury (Oxfordshire, UK). Clin Endocrinol 2010, 72:377-382.

5. Karga HJ, Alexander JM, Hedley-Whyte ET, Klibanski A, Jameson JL: Ras mutations in human pituitary tumors. J Clin Endocrinol Metab 1992, 74:914-919.

6. Cai WY, Alexander JM, Hedley-Whyte ET, Scheithauer BW, Jameson IL, Zervas NT, Klibanski A: Ras mutations in human prolactinomas and pituitary carcinomas. J Clin Endocrinol Metab 1994, 78:89-93.

7. Quereda V, Malumbres M: Cell cycle control of pituitary development and disease. J Mol Endocrinol 2009, 42:75-86.

8. Pei L, Melmed S: Isolation and characterization of a pituitary tumortransforming gene (PTTG). Mol Endocrinol 1997, 11:433-441.

9. Vlotides G, Eigler T, Melmed S: Pituitary tumor-transforming gene: physiology and implications for tumorigenesis. Endocrine Reviews 2007, 28:165-186.

10. Zhang X, Horwitz GA, Heaney AP, Nakashima M, Prezant TR, Bronstein MD, Melmed S: Pituitary tumor transforming gene (PTTG) expression in pituitary adenomas. J Clin Endocrinol Metab 1999, 84:761-767.

11. Saez C, Japon MA, Ramos-Morales F, Romero F, Segura DI, Tortolero M, Pintor-Toro JA: Hpttg is over-expressed in pituitary adenomas and other primary epithelial neoplasias. Oncogene 1999, 18:5473-5476.

12. The Hapmap Database. [http://hapmap.ncbi.nlm.nih.gov/cgi-perl/gbrowse/ hapmap28_B36].

13. Carlson CS, Eberle MA, Rieder MJ, Yi Q, Kruglyak L, Nickerson DA: Selecting a maximally informative set of single-nucleotide polymorphisms for association analyses using linkage disequilibrium. Am J Hum Genet 2004, 74:106-20.

14. Barrett JC, Fry B, Maller J, Daly MJ: Haploview: analysis and visualization of LD and haplotype maps. Bioinformatics 2005, 21:263-265.

15. Shi $Y Y, H e$ L: SHEsis, a powerful software platform for analyses of linkage disequilibrium, haplotype construction, and genetic association at polymorphism loci. Cell Res 2005, 15:97-98.

16. Salehi F, Kovacs K, Scheithauer BW, Lloyd RV, Cusimano M: Pituitary tumortransforming gene in endocrine and other neoplasms: a review and update. Endocrine-Related Cancer 2008, 15:721-743.

17. Zou H, McGarry TJ, Bernal T, Kirschner MW: Identification of a vertebrate sister-chromatid separation inhibitor involved in transformation and tumorigenesis. Science 1999, 285:418-422.

18. Zhang X, Horwitz GA, Prezant TR, Valentini A, Nakashima M, Bronstein MD, Melmed S: Structure, expression, and function of human pituitary tumortransforming gene (PTTG). Mol Endocrinol 1999, 13:156-166.

19. Yu R, Lu W, Chen J, McCabe CJ, Melmed S: Overexpressed pituitary tumor-transforming gene causes aneuploidy in live human cells. Endocrinology 2003, 144:4991-4998.

20. Chesnokova V, Kovacs K, Castro AV, Zonis S, Melmed S: Pituitary hypoplasia in $\mathrm{Pttg}-/$ - mice is protective for $\mathrm{Rb}+/$ - pituitary tumorigenesis. $\mathrm{Mol}$ Endocrinol 2005, 19:2371-2379.

21. Chesnokova V, Zonis S, Rubinek T, Yu R, Ben-Shlomo A, Kovacs K, Wawrowsky K, Melmed S: Senescence mediates pituitary hypoplasia and restrains pituitary tumor growth. Cancer Res 2007, 67:10564-10572.

22. Donangelo I, Gutman S, Horvath E, Kovacs K, Wawrowsky K, Mount M, Melmed S: Pituitary tumor transforming gene overexpression facilitates pituitary tumor development. Endocrinology 2006, 147:4781-4791.

23. Holt $L$, Krutchinsky AN, Morgan DO: Positive feedback sharpens the anaphase switch. Nature 2008, 454:353-357.

24. Hamid T, Kakar SS: Pttg/securin activates expression of p53 and modulates its function. Mol Cancer 2004, 3:18.

25. McCabe CJ, Khaira JS, Boelaert K, Heaney AP, Tannahill LA, Hussain S, Mitchell R, Olliff J, Sheppard MC, Franklyn JA, Gittoes NJ: Expression of pituitary tumour transforming gene (PTTG) and fibroblast growth factor2 (FGF-2) in human pituitary adenomas: relationships to clinical tumour behaviour. Clin Endocrinol (Oxf) 2003, 58:141-150. 
26. Pei L: Identification of c-myc as a down-stream target for pituitary tumor-transforming gene. J Biol Chem 2001, 276:8484-8491.

27. Romero F, Multon MC, Ramos-Morales F, Dominguez A, Bernal JA, PintorToro JA, Tortolero M: Human securin, hPTTG, is associated with Ku heterodimer, the regulatory subunit of the DNA-dependent protein kinase. Nucleic Acids Res 2001, 29:1300-1307.

28. Giacomini D, Haedo M, Gerez J, Druker J, Paez-Pereda M, Labeur M, Stalla GK, Arzt E: Differential gene expression in models of pituitary prolactin-producing tumoral cells. Horm Res 2009, 71:88-94.

\section{Pre-publication history}

The pre-publication history for this paper can be accessed here: http://www.biomedcentral.com/1471-2350/12/44/prepub

doi:10.1186/1471-2350-12-44

Cite this article as: Chen et al.: Pituitary tumor transforming gene-1 haplotypes and risk of pituitary adenoma: a case-control study. BMC Medical Genetics 2011 12:44.

\section{Submit your next manuscript to BioMed Central} and take full advantage of:

- Convenient online submission

- Thorough peer review

- No space constraints or color figure charges

- Immediate publication on acceptance

- Inclusion in PubMed, CAS, Scopus and Google Scholar

- Research which is freely available for redistribution

Submit your manuscript at www.biomedcentral.com/submit 